Abstract

\title{
Fundraising in New Zealand Schools ${ }^{\dagger}$
}

\author{
Vicky Rowe, Maria Anna Choukri * and Megan Harlick \\ Department of Nursing, Midwifery, and Allied Health, Ara Institute of Canterbury, Christchurch 8140, \\ New Zealand; markandvicky74@gmail.com (V.R.); megan.harlick@ara.ac.nz (M.H.) \\ * Correspondence: maria.choukri@ara.ac.nz \\ + Presented at the 2018 Nutrition Society of New Zealand Annual Conference, Auckland, New Zealand, \\ 28-30 November 2018.
}

Published: 12 March 2019

Background: Learning healthy nutritional behaviours is important in the early years of a child's life. The school environment gives the government the perfect opportunity to teach children about healthy eating and to encourage lifelong habits around nutrition. Due to financial need, schools have to fundraise, and very often, discretionary food is used for fundraising activities. Previous research in NZ (2002) showed high percentages of these types of foods being used to fundraise This study examined types of fundraising activities in New Zealand schools, primary fundraising sources and if schools have changed their fundraising practices and if there are any differences in fundraising habits across both the regions and deciles, and if schools have a nutrition policy.

Methods: All eligible primary schools from all 16 geographical regions of New Zealand were invited to complete a survey distributed via email link by the New Zealand Parent Teacher Association (NZPTA). All respondents were asked questions about type of their fundraising activities.

Results: A total of 364 schools (14.9\% response rate) with a similar proportion of all deciles completed the survey. The most popular fundraising options were pizza/pies/hot dogs/sausages/toasted sandwiches (57\% overall, more popular in deciles 1-6) mufti days (56\%), and dress up days (50\%), with the least favoured option being fruit and vegetables (6\%). Schools are using non-food and beverage items such as 2 nd hand clothing sales, family portrait sessions and calendars. Often, parents were not sure if the school had a nutrition policy.

Conclusions: Compared to previous studies, the results show an increase in the percentage of schools using pizza/pies/hot dogs/sausages from $42 \%$ to $57 \%$. On the other hand, there has been a decrease in the use of chocolate for fundraising from $60 \%$ to $22 \%$. Schools need to be supported in their use of non-food fundraising options.

(C) 2019 by the authors. Licensee MDPI, Basel, Switzerland. This article is an open access article distributed under the terms and conditions of the Creative Commons Attribution (CC BY) license (http://creativecommons.org/licenses/by/4.0/). 